\title{
The periosteum-a surface for all seasons
}

\section{E. Seeman}

Published online: 15 February 2007

(C) International Osteoporosis Foundation and National Osteoporosis Foundation 2007

\section{Erratum to: Osteoporos Int \\ DOI 10.1007/s00198-006-0296-6}

This article was unfortunately published with an incorrect version of the legend to Fig. 3. The correct legend is given here.

Fig. 3 Differences in the extent of periosteal and cortical modelling and remodelling at each point around the perimeter of a cross section deposit or remove varying amounts of bone. Along and around a tubular bone, this produces cross sections differing in size and shape, and differences in cortical thickness around the perimeter of femoral neck or tibia. Femoral neck and tibia sections courtesy of R. Zebaze and Q. Wang, Austin Health, University of Melbourne

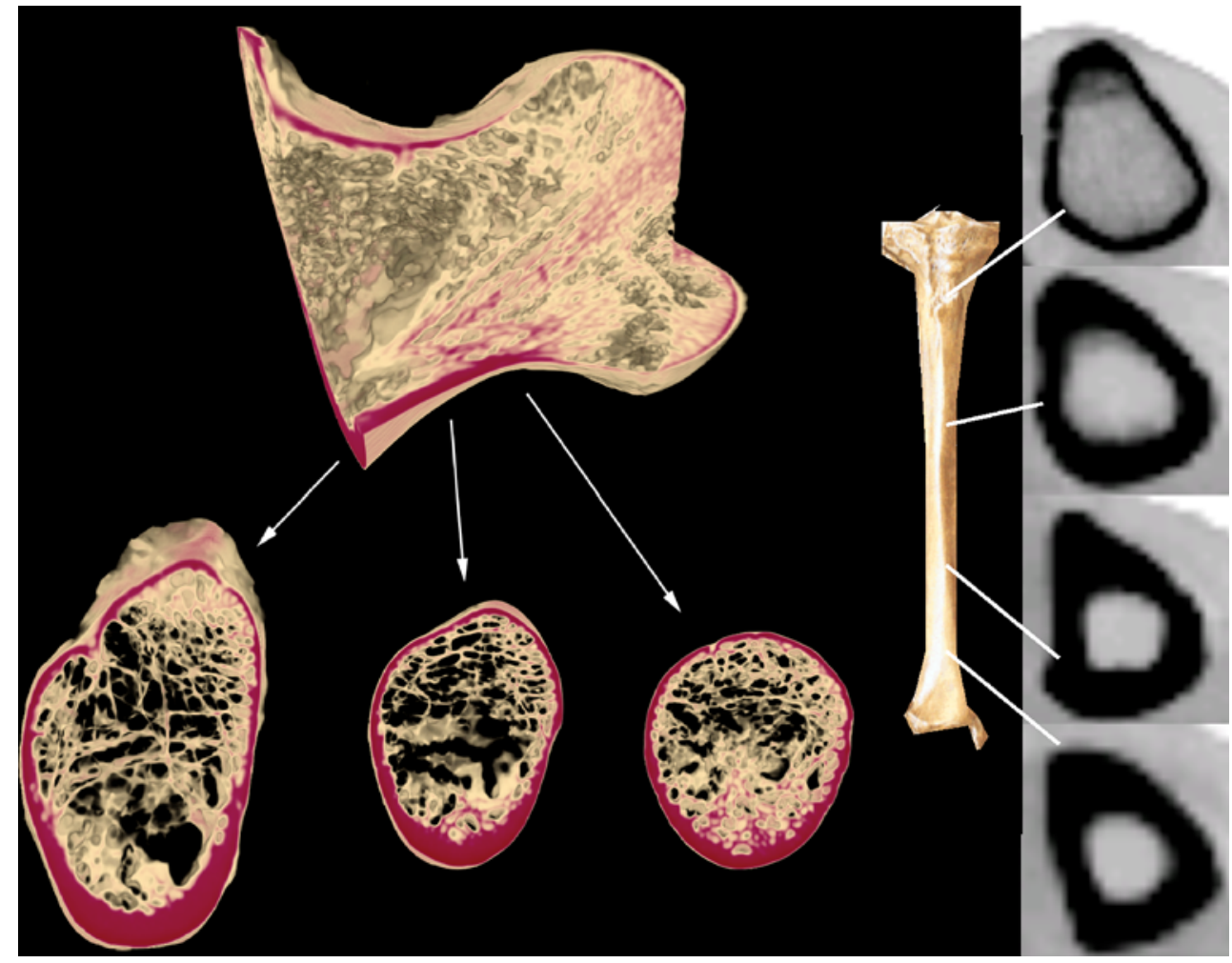

The online version of the original article can be found at http://dx.doi. org/10.1007/s00198-006-0296-6

E. Seeman $(\bowtie)$

Austin Health, University of Melbourne,

Melbourne, Australia

e-mail: egos@unimelb.edu.au 